\title{
Venture Capital and Industrial Structure Upgrading from the Perspective of Spatial Spillover
}

\author{
Li Yao ${ }^{1,2,3}$, Jie Lu ${ }^{4}$ and Pingjun Sun $1,2, *$ (1) \\ 1 School of Geographical Sciences, Southwest University, Chongqing 400715, China; yao66625@swu.edu.cn \\ 2 State Cultivation Base of Eco-agriculture for Southwest Mountainous Land, Southwest University, \\ Chongqing 400715, China \\ 3 Key Laboratory of Geospatial Technology for the Middle and Lower Yellow River Regions, \\ Henan University, Kaifeng 475001, China \\ 4 Department of Surveying and Planning, Shangqiu Normal University, Shangqiu 476000, China; \\ lujie1126@126.com \\ * Correspondence: sunpj031@nenu.edu.cn; Tel.: +86-1563-682-6076
}

Received: 24 October 2019; Accepted: 21 November 2019; Published: 26 November 2019

\begin{abstract}
As an emerging financial entity, venture capital has a significant impact on regional development and local production systems. Previous research results pay more attention to the spatial distribution and agglomeration of venture capital but pay less attention to its spatial externality. This paper used the panel data of 31 provincial-level regions in China from 2003 to 2017 to measure the industrial structure upgrading level from the two dimensions of rationalization of industrial structure and upgrading of industrial structure. Based on regional heterogeneity that determines industrial structure upgrading, local effects and externalities of venture capital, and omission factors, this paper constructs spatial econometrics models of venture capital and industrial structure upgrading. Firstly, venture capital and industrial structure upgrading all have obvious spatial autocorrelation and form different agglomeration areas in local areas. Therefore, regional venture capital and industrial structure upgrading are closely related to regional location factors. China's venture capital has unique spatial attributes. Secondly, venture capital has a significant role in promoting the industrial structure upgrading, although its simulative effect is weak. In addition, in order to further explore the influence mechanism of regional industrial structure upgrading, this paper found the local fixed asset investment level and R\&D intensity promoted the upgrading process of local industrial structure at a significant level. The study of this paper has important implications for the formulation of appropriate regional venture investment policies to promote the optimization and upgrading of industrial structures and sustainable development during the transition period of economic development.
\end{abstract}

Keywords: capital venture; industrial structure upgrading; spatial econometrics model; spatial spillover effect

\section{Introduction}

As China's economy enters a new normal, the upgrading of its industrial structure has led to unprecedented challenges in China. As an emerging financial entity, venture capital, whose core lies in the value exchange and expansion of capital value across time and space, has a significant impact on regional development and local production systems [1]. Venture capital originated in the United States in the 1940s and has been popular in developed countries for many years [2,3]. Venture capital mainly aims at long-term equity investment in emerging industries (mainly high-tech industries) that are in the start-up stage, not listed and have the characteristics of rapid development [4]. Since 
the establishment of the first venture capital fund in 1985, China's venture capital has experienced a short history but rapid development. By the end of December 2018, there have been 24,448 private fund managers registered with the Asset Management Association of China. As the trans-regional investment venture capital shapes new urban industry and spatial systems, it influences the economic transition and industrial restructuring in different regions through the specialization of capital, and influences the regional, national, and even global financial geographic spatial patterns. Therefore, it has become a major area of financial geography research [5]. Some research and results from developed countries show that an effective venture capital system plays an irreplaceable role in the industrial upgrading of a country, and the degree of development of venture capital industry directly determines the degree of development of a technology industry and the optimization of the industrial structure of a country (or region) [6]. However, the previous research in China paid more attention to the spatial distribution and agglomeration of venture capital, and paid less attention to its spatial externality [7-9].

According to the previous theory and experience, venture capital plays an important role in regional economic growth, technological innovation, and industrial development [10-14]. Firstly, venture capital will have an impact on regional economic development. For example, some scholars found that venture capital can significantly accelerate the growth of enterprises through resource integration, thus improving the economic development capacity of the region [10]. Secondly, venture capital has an impact on regional industrial innovation and regional innovation systems. For example, many scholars found that venture capital can promote the improvement of patent technology and total factor productivity, and it played an obvious role in promoting high-tech industry [11-13]. Thirdly, some scholars believed that the cluster of venture capital also plays an important role in improving the self-benefit of venture capital enterprises [14].

According the theory and practice of developed countries, we can find that the venture capital plays an important role in the process of industrial transformation and upgrading. In recent years, scholars have gradually begun to pay attention to the impact of venture capital on industrial structure upgrading, such as whether there is a systematic correlation between venture capital and industrial structure upgrading. For example, India economist T Satyana Chary pointed out that the development of a venture capital industry was conducive to solving industrial problems and optimizing industrial structures [15]. By doing the empirical studies, Zhao and Jin analyzed a mechanism where venture capital promoted green innovation of the entity industry, and found that venture capital could more effectively enhance the green innovation capacity of the Chinese entity industry than bank loans [16]. Ding and Jin used Zhejiang province as an example to discuss the role of equity investment in systematic economic transformation, using the dimensions of theory and practice [17]. Florida and Peneder et al. believed that venture capital had a positive impact on enterprise innovation behavior, and that enterprise innovation was also an important factor in industrial transformation and upgrading [18-20]. $\mathrm{Xu}$ and Wang studied the Yangtze river delta region and found that venture capital had a positive impact on enterprise operation efficiency and regional industrial structure optimization from micro and medium perspectives [21].

The literatures on the relationship between venture capital and the industrial structure upgrading structure has been carried on beneficial exploration, but most of the above research used the traditional statistics and classical quantitative regression analysis in the time dimension and ignored the mutual influence of venture capital between different regions. According to the first law of geography proposed by Tobler (1970), there is always a certain interaction between economic behaviors in different regions, which gradually weakens with the increase of spatial distance [22]. More and more research has begun to pay attention to the degree of spatial interaction of economic phenomena and used spatial econometric models to analyze the spatial correlation and spillovers. For example, there have been many research articles on the spillover effect of finance and industry agglomeration on economic growth $[23,24]$. The spatial econometric model was used to study the relationship between technology, knowledge spillover and regional innovation $[25,26]$. Many studies have used the spatial econometric method to study the convergence of regional economies $[27,28]$. Therefore, in this paper, there are 
two aspects that can be further studied: Firstly, the analysis of the impact of venture capital on the upgrading of industrial structure is still at the theoretical level. The study on the externality of venture capital mainly focuses on its influence on the improvement of regional high technology levels. However, there are few discussions on the relationship between venture capital and industrial structure upgrading. Secondly, only a few scholars have analyzed the spillover principle of the upgrading of industrial structure of venture capital from the perspective of spatial spillover, and a normative theoretical framework has not yet been formed.

The development of venture capital industry in a region will influence and drive the demand for high-tech industry input in the region and surrounding areas, and further affect the upgrading of industrial structure. Therefore, the proposition that venture capital promotes the upgrading of industrial structure has been supported by empirical research. However, due to differences in measurement indicators and measurement methods, it is still necessary to further explore the extent of the impact of venture capital on industrial structure upgrading and whether there is spatial spillover effect. In order to test this hypothesis, we will conduct the following research and attempt to achieve the following research objectives: Firstly, this paper will test whether there are spatial autocorrelation of venture capital and industrial structure upgrading. Secondly, on the basis of constructing the spatial weight matrix, this paper will establish the spatial econometric model to discuss whether there are spatial spillover effect of venture capital and industrial structure upgrading. Then, we will continue to discuss how this effect affects industrial structure upgrading. Finally, this paper will put forward corresponding policy suggestions to promote the development of venture capital industry and regional sustainable development.

\section{The Influence Mechanism and Theoretical Model Construction}

\subsection{The Influence Mechanism of Venture Capital on Industrial Structure Upgrading}

The upgrading of industrial structure needs to be coordinated with favorable economic, social, and policy conditions [29]. Scholars at home and abroad have done a lot of research on the factors affecting the upgrading of industrial structure. Lall and Ergas believed that institution and policy were important factors affecting industrial transformation and upgrading [30,31]. Gereffi analyzed the relationship between international trade and industrial upgrading by examining the social and organizational dimensions of international trade networks [32]. Amin and Goddard provided a brief examination of the nature and significance of a number of relationships between technical change and innovation and the processes of economic growth and industrial structural change [33]. Greenwood and Jovanovic pointed out that finance development and economic growth characterized by changes in industrial structure are mutually causative [34]. Chen and Yang systematically analyzed the mechanism of the influence of financial structures on the adjustment of industrial structure [35]. In addition to this, many other studies have shown that foreign investment, opening-door policies, and enterprise capital are also important factors which affect industrial structure transition [36-40].

Venture capital mainly plays a role in the incubation stage of industry, which is a crucial stage of high-tech industrialization [41]. In the incubation stage, because the new products have not been produced, there is no market supply and demand relationship. The product market in this stage is usually difficult to develop, because it has the risk of product chain disruption. At the same time, venture capital institutions will provide value-added services and help enterprises to formulate their long-term development strategies. Therefore, the development of high-tech industries with investment risks needs the support of venture capital to be stable and sustainable. The rapid incubation and change of high and new technology makes the high and new technology industries develop continuously. Therefore, through promoting the technological innovation of small and medium-sized enterprises, venture capital can better form the industrial cluster with benign development, accelerate the technology transfer and spillover within the industrial cluster, and improve the technical level of industrial clusters. 
Capital is inherently profit-driven, and venture capital is no exception. Venture capital not only improves economic efficiency, but also optimizes the allocation of financial resources [42,43]. The credit market and capital market control the direction of capital flow, so it can make the capital flow to the most efficient areas, thus achieving the optimal allocation of financial resources. The process of venture capital providing funds to the economy and society is also the process of financial assets choosing industrial scope. The flow and allocation of resources and funds between industrial sectors is the inevitable requirement of industrial structure optimization. To realize the optimization of an industrial structure, it is necessary to let the limited resources flow freely among various sectors of the industry, to achieve the optimal allocation of resources. Venture capital can effectively guide resources from inefficient departments to efficient departments, from declining industries to sunrise industries with development potential, from high-pollution industries to green and environmental protection industries. The flow of capital is also the process of the corresponding transfer of labor and various resources. The departments that acquire resources can develop faster and better, while the development of departments that lose resources will be increasingly restricted, so that eventually they will be eliminated. This kind of dynamic adjustment continuously optimizes and upgrades the industrial structure. The influence mechanism of venture capital on industrial structure upgrading is shown as Figure 1.

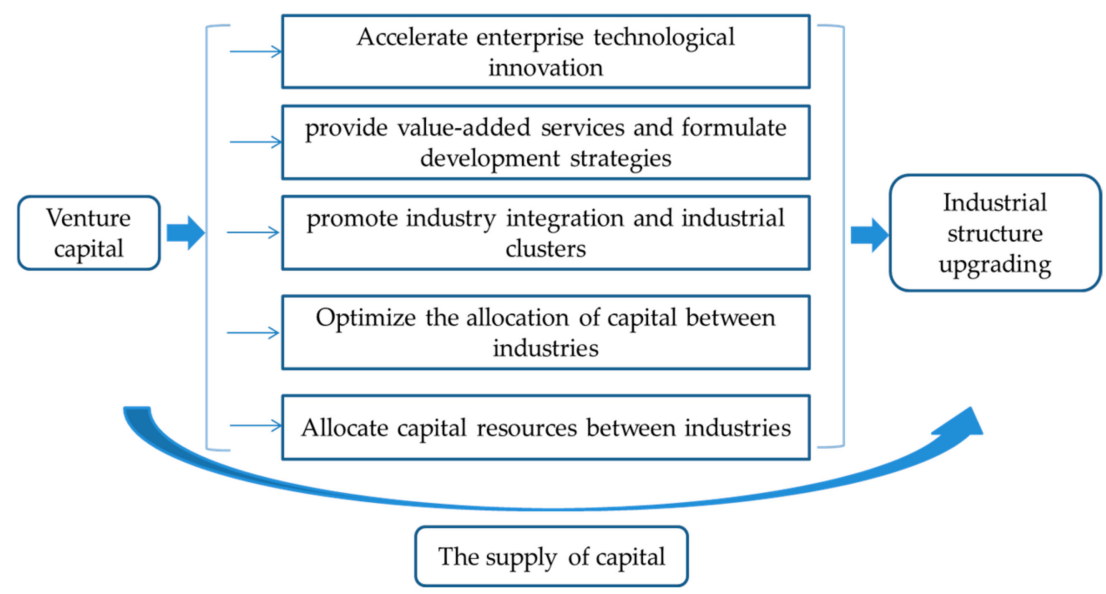

Figure 1. The influence mechanism of venture capital on industrial structure upgrading.

\subsection{Model Construction}

In this paper, the following aspects should be considered first before the model is established: Firstly, spatial heterogeneity exists in a regional industrial structure. The evolution of industrial structure is a dynamic cumulative process. Due to the long-term cumulative effects of geographical location, resource endowment conditions, political, economic and cultural conditions, scientific research, and education levels and marketization levels, a regional industrial structure is easily susceptible to path dependence and the Matthew effect, so that it needs to have spatial heterogeneity [44]. Secondly, this paper needs to consider the local effects and externalities of venture capital. Venture capital has the preference to invest in the high-tech industry, which has a direct effect on local industrial structures. The multiplier effect and crowding out effect of venture capital continue to spread, so as to influence surrounding areas or other areas beyond the region and produce positive or negative externalities. There are some surprising positive effects, but there are also some difficult negative effects [6]. Thirdly, there are some missing factors to consider in model construction. In addition to venture capital, there are many non-venture capital factors affecting the industrial structure. These factors include both factors that are difficult to quantify or observe (such as culture, concepts, economy, risk appetite, and unexpected shocks) and factors that are quantifiable or observable (such as consumption habits, 
investment, innovation, and finance). Only a model that includes the factors mentioned above can reveal the influence of venture capital on industrial structures.

With the development of spatial econometrics, the models and methods based on panel data are becoming more and more mature. Anselin's early research on a Spatial Econometric Model was mainly based on cross-sectional data [45]. However, in 2008, he pointed out that a spatial lag term and spatial error term can be included in the Spatial Panel Model when spatial dependence exists among observation individuals, namely the Spatial Lag Model (SLM) and Spatial Error Model (SEM) based on panel data [46]. Subsequently, LaSage and Pace extended the Spatial Lag Model and proposed the Spatial Durbin Model (SDM), which includes both the spatial lag term and the spatial lag term of explained variables [47]. Referring to the modeling technology of spatial econometrics emerging in recent years, this paper divides the level of industrial institutions into four effects, namely, regional heterogeneity $(a)$, local current effect of venture capital $\left(x \beta_{1}\right)$, the external effect of venture capital $\left(W x \beta_{2}\right)$, and omission factor effect $(z \theta)$, which can be expressed as follows:

$$
y=a+x \beta_{1}+W x \beta_{2}+z \theta
$$

In the formula (1), $x$ represents the venture capital level, $W$ represents the space weight matrix expressed by latitude and longitude coordinates of the region, and $z$ represents all the missing factors in non-financial expenditures. So $x \beta_{1}$ stands for the current effect of venture capital, and $W x \beta_{2}$ stands for the external effect of venture capital. As for the missing factors $(z)$, according to common sense, culture, regulations, consumption, investment, and technology among regions all have mutual influences, and the externalities are obvious. Therefore, if there is spatial dependence or a neighbor effect between regions, then the formula can be expressed as follows:

$$
\begin{gathered}
z=\rho W z+v \\
z=\left(I_{n}-\rho W\right)^{-1} v .
\end{gathered}
$$

Due to modeling needs, according to the generation process of spatial data, this paper converts Equation (2) into the form of Equation (3). According to formula (1), we get the following model.

$$
y=a+x \beta_{1}+W x \beta_{2}+\left(I_{n}-\rho W\right)^{-1} \theta v .
$$

For Equation (4), according to common practice, there may also be a correlation between omitted factors and venture capital. For example, venture capital has an impact on regional innovation and consumption levels through the crowding out effect. Therefore, we assume that there is a linear correlation between venture capital and omitted factors.

$$
\theta v=x \gamma+\varepsilon, \varepsilon \sim N\left(0, \sigma^{2} I_{n}\right)
$$

Formula (5) shows that the omitted factors, by decomposing their externalities and their relationship with venture capital, obtain the normal distribution of random impact term $\varepsilon$ with a mean value of 0 and constant variance. Although this may be close to reality, it cannot guarantee that there is no rule of variance. If there is a rule of variance, then Bayesian estimation is superior to likelihood estimation when estimating parameters. Through formula transformation, we finally get the following formula.

$$
y=\rho W y+\left(I_{n}-\rho W\right) a+x\left(\beta_{1}+\gamma\right)+W x\left(-\rho \beta_{1}-\rho W \beta_{2}\right)+\varepsilon .
$$

Then, we mark $\alpha_{0}=\left(I_{n}-\rho W\right) a, \alpha_{1}=\beta_{1}+\gamma, \alpha_{2}=-\rho \beta_{1}-\rho W \beta_{2}$, and Equation (8) can be expressed as follows:

$$
y=\rho W y+a_{0}+\ln x \alpha_{1}+W \ln x \alpha_{2}+\varepsilon .
$$


Apparently, formula (7) is a Spatial Durbin Model (SDM), and it is as the benchmark model of this paper. Considering the model parameters of the formula (7) are different due to having different dimensions, it is impossible to make a comparative judgment on the impact of venture capital levels of different levels on industrial structure. In order to make the economic significance of the parameters clearer, we adopt the form of the Log-Log model in which the parameters are not affected by the dimension, so the paper can compare and analyze the influence of different levels of venture capital. The Log-Log model can be expressed as follows:

$$
\ln y=\rho W \ln y+a_{0}+\ln x \alpha_{1}+\ln x \alpha_{2}+\varepsilon .
$$

In addition, according to whether the parameter of Equation (8) is 0 or not, a regression model (OLS), spatial lag model (SLX) and spatial autoregressive model (SAR) can be derived by evolution. In practice, according to data information, the most reasonable models that can reflect the relationship between venture capital and industrial structure should be determined. In this way, these models are taken as alternative models in the following forms:

$$
\begin{gathered}
\ln y=a_{0}+\ln x \alpha_{1}+\varepsilon(\mathrm{OLS}) \\
\ln y=a_{0}+\ln x \alpha_{1}+W \ln x \alpha_{2}+\varepsilon(\mathrm{SLX}) \\
\ln y=\rho W \ln y+a_{0}+\ln x \alpha_{1}+\varepsilon(\mathrm{SAR}) .
\end{gathered}
$$

\subsection{Spatial Correlation Test}

\subsubsection{Global Spatial Autocorrelation}

Before the spatial measurement, the spatial autocorrelation test of explanatory variables is firstly carried out, and Moran's I is generally adopted as the spatial correlation measure index. Global Moran's I can judge whether the variables are clustered or dispersed in space, while local Moran's I can judge the degree of spatial clustering of the variables by combining scatter plots. Global and local Moran's I can be expressed as follows:

$$
\operatorname{Moran}^{\prime} I=\frac{\sum_{i=1}^{n} \sum_{j=1}^{n} W_{i j}\left(Y_{i}-\bar{Y}\right)\left(Y_{j}-\bar{Y}\right)}{S^{2} \sum_{i=1}^{n} \sum_{j=1}^{n} W_{i j}} .
$$

In the formula, $S^{2}=\frac{1}{n} \sum_{i=1}^{n}\left(Y_{i}-\bar{Y}\right)$, and $\bar{M}=\frac{1}{n} \sum_{i=1}^{n}{ }_{i} . W_{i j}$ is the spatial weight matrix. $Y_{i}$ represents the observed value of region I. $N$ is the total number of regions. $W$ is the spatial weight matrix. Moran's I can be regarded as the product sum of observed values of various regions, whose value range is between -1 and 1 . If economic behaviors of various regions are positively correlated in space, then its value should be large.

\subsubsection{Local Spatial Autocorrelation}

The commonly used measures of local spatial autocorrelation are the Moran scatter plot and Lisa statistical indicators. The Moran scatter diagram is used to express the relationship between variables and their spatial lag vectors, which can be used to identify local spatial correlation patterns. The Moran scatter diagram is divided into four quadrants. The first and third quadrants represent positive spatial correlation, while the second and fourth quadrants represent negative spatial correlation. Local 
Moran's I, is designed to disperse the value of Moran's I to each region, and its calculation formula is as follows:

$$
I_{i}=\frac{\left(X_{i}-\bar{X}\right)}{S_{i}} \sum_{j=1}^{n} w_{i j}\left(X_{j}-\bar{X}\right)
$$

If $I_{i}>0$, then the sample is classified into HH (High-High) or LL (Low-Low) type; If $I_{i}<0$, the sample is classified into HL (High-Low) or LH (Low-High) type. HH type means that the high-value area is surrounded by the high-value area; LL type means that the low-value area is surrounded by the low-value area; HL means that the high-value area is surrounded by the low-value area; LH means that the low-value area is surrounded by the high-value area.

\subsection{Setting of the Spatial Weight Matrix}

In the selection of spatial weight matrix, the distance attenuation function is adopted to construct the spatial distance matrix. However, the geographical factor is not the only factor that determine the spatial correlation, and geographical distance matrix cannot fully explain the degree of interdependence of spatial clustering of venture capital. Therefore, based on the geographical weight of the economic development level of each region, this paper weighted the proportion of the average per capita GDP. So, the economic space matrix was expressed as the product of the geographical distance weight matrix and the diagonal matrix of the proportion of per capita GDP (Tan 2012). The specific form is:

$$
\begin{gathered}
W=w \times \operatorname{diag}\left(\frac{\overline{x_{1}}}{\bar{x}}, \overline{\frac{x_{2}}{\bar{x}}}, \ldots, \frac{\overline{x_{n}}}{\bar{x}}\right) \\
\overline{x_{i}}=\frac{1}{t_{1}-t_{0}+1} \sum_{t=t_{0}}^{t_{1}} x_{i t}, \bar{x}=\frac{1}{n\left(t_{1}-t_{0}+1\right)} \sum_{t=t_{0}}^{t_{1}} \sum_{i=1}^{n} x_{i t}
\end{gathered}
$$

where $t$ is the number of time periods, $n$ is the number of regions, and $x$ is the per capita GDP of regions. We normalized the spatial weight matrix so that the sum of the elements in each row of the matrix is 1 .

\section{Variable Selection and Data Sources}

\subsection{Variable Selection}

\subsubsection{Explained Variable}

The upgrading of industrial structure includes two dimensions: the advanced level and rationalization level.

Industrial structure advanced level: The upgrading of the industrial structure is a process in which the main body of industrial structure of a country (or region) progresses successively along the three industries, reflecting the level, stage, and development direction of the economy. In this paper, the ratio of the output value of the second and third industries to Gross Domestic Product is adopted as the measurement index of the industrial structure upgrading. The higher the value is, the higher the degree of upgrading is.

Industrial structure rationalization level: Based on the connotation of deviation degree of traditional industrial structure, this paper introduces the Taier index. While retaining the theoretical significance and economic connotation of the original index, the relative importance of industry is added to improve the original deviation degree index. The calculation formula is shown in formulas (15) and (16).

$$
\begin{gathered}
T_{i}=\ln \left(\frac{M_{i} / M}{L_{i} / L}\right) \\
T=\sum_{i=1}^{3}\left(\frac{M_{i}}{M}\right) \times\left|\ln \left(\frac{M_{i} / M}{L_{i} / L}\right)\right|
\end{gathered}
$$


where $T_{i}$ stands for the $i t h$ industry rationalization level. $T$ is the overall rationalization level of the industrial structure, $M_{i}$ represents the output value of the ith industry, $L_{i}$ represents the employment number of the ith industry, $M$ represents the gross regional product, and $L$ represents the total employment number. If the absolute value of the index is lower, it indicates that the rationalization degree of industrial structure is higher.

This paper holds the opinion that the two aspects of Industrial structure advanced level and Industrial structure rationalization level have the same impact in the process of industrial structure upgrading. Therefore, the weight of the two aspects is 0.5 .

\subsubsection{The Explaining Variable}

Venture capital level (VC): In existing literature, the amount of venture capital and number of venture capital projects are commonly used for measurements. The information of the venture capital industry is not completely transparent, and some data cannot be obtained completely, but the disclosed information is also highly representative. In this study, the amount of venture capital in each region is selected to reflect the level of venture capital in each region.

\subsubsection{Control Variables}

The factors affecting the industrial structure upgrading can be roughly divided into several categories. Firstly, the increase of investment in an industry will undoubtedly promote the expansion and development of the industry. Increasing investment in high-level industries will directly lead to the upgrading of industrial structures. Secondly, it is obvious that technological progress can improve productivity. Talent and capital are the key factors of technological progress, and workers' mastery levels of advanced technology are the key to the transformation of technology into productivity. Thirdly, consumption plays an obvious role in driving industry, and the consumption level of residents depends on their disposable income, which in turn depends on the local economic development level. To summarize, it can be concluded that factors such as fixed asset investment, research and development investment, labor quality and economic development degree are the main factors affecting industrial development. Therefore, this paper selects these four main interfering factors as control variables, respectively. The fixed asset investment amount is used to represent the investment scale, which is represented by the symbol FIX. The amount of $R \& D$ is used to indicate the R\&D intensity, which is represented by the symbol $R D$; The proportion of the population with higher education is used to represent the quality of producers, which is represented by the symbol PHED. GDP per capita is used to express the degree of economic development, which is represented by the symbol GDP. Other minor influencing factors can be classified into the random interference category.

\subsection{Data Sources}

The research objects of this paper are 31 provinces and autonomous regions in China (excluding Hong Kong, Macao, and Taiwan), and the time span of the research is from 2003 to 2017. The original data on venture capital comes from Zero2IPO and China Venture which are the mainstream venture capital databases in China. Other data involved in this paper mainly come from the National Bureau of Statistics, Yearbook of science and technology of China, Almanac of China's Finance, and China Statistical Yearbook from previous years.

\section{Empirical Analysis and Results}

\subsection{The Characteristics of Spatial Agglomeration of Venture Capital and Industrial Structure Upgrading}

Firstly, China's venture capital has unique spatial attributes. According to the statistical data of the mount of venture capital in 2003 and 2017, the country is divided into five types of regions, as shown in Figures 2 and 3. It is not difficult to find that China's venture capital activities are mainly concentrated in the eastern coastal zone, and gradually began to transfer to the central and western 
regions, meaning the spatial distribution presents a dynamic imbalance. In 2003, Beijing, Shanghai, Guangdong and Jiangsu were the hot spots of venture capital investment, with the total investment scale accounting for $86.40 \%$. The next provinces were Shandong, Zhejiang and Hebei. However, the development of venture capital in the central and western regions lagged behind, especially in the western regions such as Xinjiang, Tibet, Shaanxi, Qinghai, Gansu, Qinghai, and so on. Secondly, as can be seen from Figure 3, the elevation value of China's industrial structure showed a rising trend from 2003 to 2017, indicating that China's industrial structure was gradually developing to a higher level on the whole.

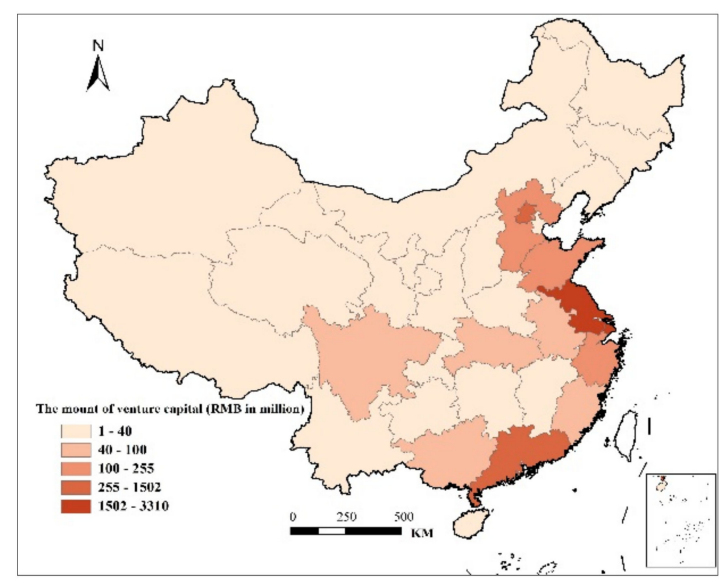

(a) 2003

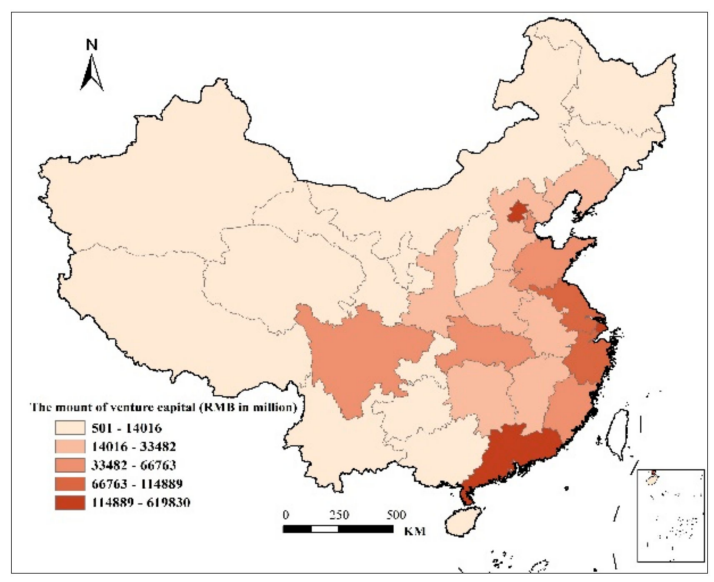

(b) 2017

Figure 2. Spatial segmentation map of China venture capital in 2003 and 2017.

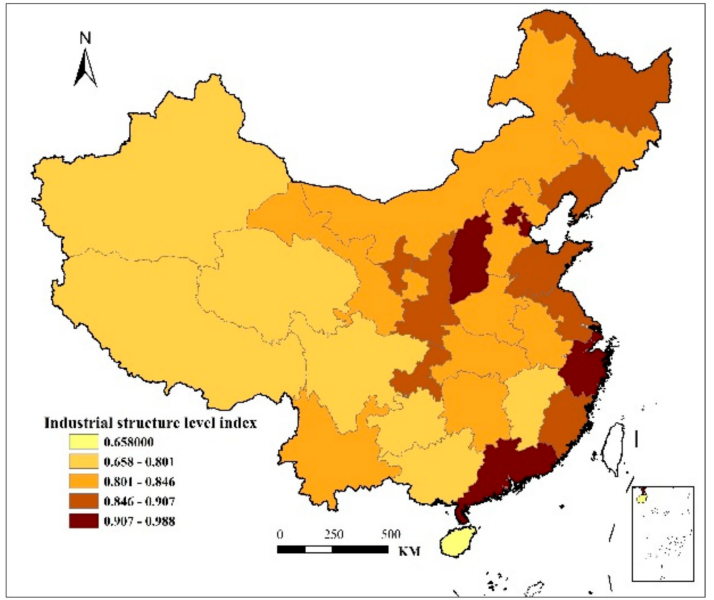

(a) 2003

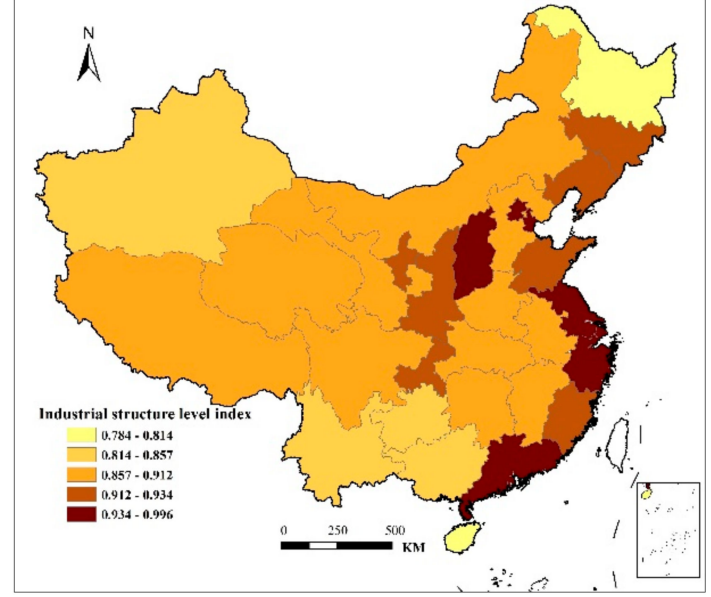

(b) 2017

Figure 3. Spatial segmentation map of China industrial structure level in 2003 and 2017.

\subsection{Spatial Correlation Analysis}

Before carrying out spatial econometric analysis, it is necessary to investigate the spatial dependence of variable data to judge whether it is suitable for the establishment of spatial econometric model. Next, Moran's index and local correlation index were adopted to analyze the spatial autocorrelation and agglomeration degree of venture capital, upgrading in geographical distribution.

As shown in Table 1, Moran's I venture capital investment level is between [0.155, 0.365], and most of the levels pass the significance test. When using the global Moran's index to examine China's industrial structure upgrade, the overall trend was gradually rising and then falling. The lowest value found was 0.155 in 2013 and the highest value was 0.365 in 2016. Moran's I of industrial structure upgrading shows an increasing trend year by year and its value range is [0.133, 0.343]. This indicates 
that there is a significant spatial clustering phenomenon occurring in China's industrial structure upgrading level. Therefore, if spatial autocorrelation is ignored and traditional linear regression OLS model is directly adopted, then model design error may occur.

Table 1. Global Moran's I of China's industrial structure upgrading from 2003 to 2017.

\begin{tabular}{ccccc}
\hline Year & $\begin{array}{c}\text { Venture Capital } \\
\text { Investment Level }\end{array}$ & Z Value & $\begin{array}{c}\text { Industrial Structure } \\
\text { Upgrading }\end{array}$ & Z Value \\
\hline 2003 & 0.228 & 2.43 & 0.283 & 3.046 \\
2004 & 0.218 & 2.36 & 0.247 & 2.816 \\
2005 & 0.240 & 2.55 & 0.250 & 2.757 \\
2006 & 0.293 & 2.94 & 0.225 & 2.422 \\
2007 & 0.173 & 1.99 & 0.133 & 1.599 \\
2008 & 0.165 & 1.96 & 0.245 & 3.073 \\
2009 & 0.174 & 2.01 & 0.218 & 2.604 \\
2010 & 0.172 & 2.00 & 0.197 & 2.460 \\
2011 & 0.252 & 2.59 & 0.255 & 2.817 \\
2012 & 0.195 & 2.02 & 0.267 & 2.863 \\
2013 & 0.155 & 1.73 & 0.343 & 4.119 \\
2014 & 0.161 & 1.77 & 0.291 & 3.407 \\
2015 & 0.176 & 1.91 & 0.256 & 2.879 \\
2016 & 0.365 & 3.59 & 0.267 & 2.747 \\
2017 & 0.209 & 2.40 & 0.266 & 3.169 \\
\hline
\end{tabular}

Figure 4 shows that the Global Moran's I of regional industrial structure upgrading in 2017 is 0.209. The local Moran's I scatter diagram is divided into four quadrants. The provinces in the HH quadrant are mainly in eastern China. For example, Shanghai, Jiangsu, Zhejiang, Shandong and Tianjin have a high level of industrial structure upgrading and are surrounded by high-level areas. The provinces that located in the LL quadrant are mainly Xinjiang, Qinghai, Chongqing, Yunnan, Ningxia, Shaanxi, and Heilongjiang. These areas are characterized by low level of industrial structure upgrading and surrounded by low-level areas. The provinces that located in the LL quadrant are Anhui, Jiangxi, Guangxi, Hainan, Hebei, Hunan, and other provinces. These provinces are characterized by low level of industrial structure upgrading but surrounded by high-level areas. The provinces that located in the LL quadrant are Beijing and Guangdong. These provinces are characterized by a relatively high level of industrial structure upgrading but surrounded by relatively low-level areas. Given that the level of industrial structure upgrading in China is spatially dependent, this paper thinks that it is necessary to consider spatial factors when constructing the model of how venture capital affects the level of industrial structure upgrading.

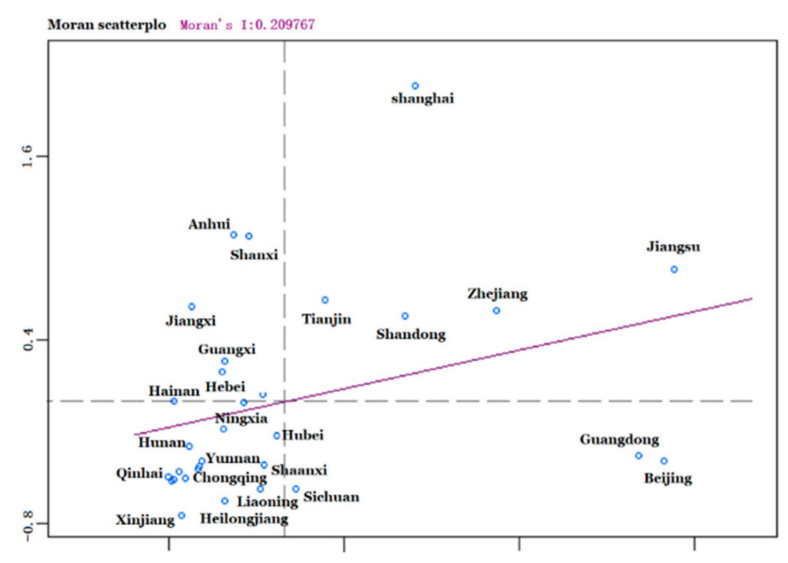

Figure 4. Local Moran's I scatter diagram of China's industrial structure upgrading level in 2017. 


\subsection{Results and Discussion}

\subsubsection{Data Test}

Firstly, in order to overcome the instability and heteroscedasticity of the data, we take the logarithmic processing on all the data. The descriptive statistics of the main variables are shown in Table 2. Then, we tested the stationarity of the data before analyzing the spatial panel data model. As shown in Table 2, the assumption that the universal unit root process (Levin, Lin and Chu-t test) and individual unit root process (Im, Pesaran, and Shin W-stat test) both reject the original hypothesis indicates that the data is stable. At last, samples from 31 provinces in China are selected for estimation (excluding Hong Kong, Macao, and Taiwan). At the same time, we chose variable intercept models that can judge individual effects. The Hausman test shows that the random effects hypothesis test has a value of 51.469 (Prob. 0.000). Therefore, we should apply the individual fixed effect model in this study. The calculation results of the model are shown in Table 2.

Table 2. Descriptive statistics of major variables and the result of Unit root test.

\begin{tabular}{|c|c|c|c|c|c|c|}
\hline Variables & Minimum & Maximum & Mean & Std. Dev. & $\begin{array}{l}\text { Levin, Lin \& } \\
\text { Chu t }\end{array}$ & $\begin{array}{l}\text { Im, Pesaran and } \\
\text { Shin W-stat }\end{array}$ \\
\hline $\operatorname{Ln}(I S U)$ & 0.3549 & 0.997 & 0.7831 & 0.1042 & $-1.383(-0.083)$ & $-3.274(0.000)$ \\
\hline $\operatorname{Ln}(V C)$ & 0.000 & 13.337 & 7.3765 & 2.4486 & $-8.954(0.000)$ & $-3.687(0.000)$ \\
\hline $\operatorname{Ln}(R D)$ & 6.2146 & 16.741 & 13.226 & 1.8613 & $-14.976(0.000)$ & $-12.523(0.000)$ \\
\hline $\operatorname{Ln}(F I X)$ & 4.8975 & 10.919 & 8.6086 & 1.1997 & $-14.295(0.000)$ & $-6.583(0.000)$ \\
\hline $\operatorname{Ln}($ PHED) & 2.7726 & 12.715 & 8.8491 & 1.8021 & $-1.191(-0.116)$ & $-5.588(0.000)$ \\
\hline $\operatorname{Ln}(G D P)$ & 8.2122 & 11.768 & 10.214 & 0.7182 & $-18.522(0.000)$ & $-9.802(0.000)$ \\
\hline
\end{tabular}

In addition, we adopted the Variance Inflation Factor (VIF) to test whether there was multicollinearity among variables in the model. In this paper, the empirical standard is used as the test standard of the model VIF value. If the model VIF value is less than 10 , it can be considered that there is no serious multicollinearity; and if the model VIF value is greater than 10, it can be considered that there is serious multicollinearity. The multicollinearity test results are in Table 3. Obviously all the variables of the model passed the multicollinearity test.

Table 3. The VIF test results of control variables.

\begin{tabular}{cccccc}
\hline Variables & $\operatorname{Ln}(V C)$ & $\operatorname{Ln}(R D)$ & $\operatorname{Ln}(F I X)$ & $\operatorname{Ln}(P H E D)$ & $\operatorname{Ln}(G D P)$ \\
\hline Coefficient Variance & 2.63 & 1.87 & 1.88 & 4.13 & 3.33 \\
\hline
\end{tabular}

\subsubsection{Estimation Results and Analysis of Spatial Econometric Model}

By using the data of regional structure upgrading level, regional venture investment level, investment scale, research and development strength, quality of producers, and the degree of economic development index data from 2003 to 2017, this paper used Matlab2012 calculation software to estimate and test the model. After constructing spatial econometric model, we quantitatively analyzed the variable degree of impact on the upgrading of China's industrial structure.

OLS estimates found that the goodness of fit was 0.711 , and most of the variables passed the significance test. By comparing the estimated results of SLM and SDM and the corresponding goodness of fit, it is more reasonable to consider spatial factors to explain the impact of venture capital on the upgrading of industrial structure. The adjustment $\mathrm{R}^{2}$ of the spatial econometric model is larger than that of the traditional basic panel data model, among which the adjustment $\mathrm{R}^{2}$ of the SDM model is the largest (0.965), and the logarithmic likelihood function of the SDM model is the largest (867). At the same time, according to the judgment criteria of Anselin (2004) and Elhorst (2014), combined with goodness of fit test, natural logarithm function value, likelihood ratio, Akaike Information Criterion, etc., we selected the region and time double fixed SDM model in this paper. 
According to the estimates in Table 4, under the influence of different spatial weights, various variables have different influences on industrial structure upgrading. Firstly, the $\rho$ coefficient of spatial correlation has passed the significance test level of $1 \%$, and the $\rho$ coefficient is larger when the economic distance spatial weight matrix is applied, which indicates that the upgrading process of regional industrial structure has an obvious spatial spillover effect. Moreover, regardless of the kind of spatial weight matrix selected, the spatial lag term of regional industrial structure upgrading passed the $1 \%$ significance level test, and the coefficient was positive.

Table 4. The estimation results of spatial econometric model from the national level.

\begin{tabular}{|c|c|c|c|c|c|}
\hline \multirow[b]{2}{*}{ Variables } & \multirow[b]{2}{*}{ OLS } & \multicolumn{2}{|c|}{ SLM } & \multicolumn{2}{|c|}{ SDM } \\
\hline & & $\begin{array}{l}\text { Geographical } \\
\text { Distance Matrix }\end{array}$ & $\begin{array}{c}\text { Economic } \\
\text { Distance Matrix }\end{array}$ & $\begin{array}{l}\text { Geographical } \\
\text { Distance Matrix }\end{array}$ & $\begin{array}{c}\text { Economic } \\
\text { Distance Matrix }\end{array}$ \\
\hline$V C$ & $0.136^{* *}$ & $0.158^{* *}$ & $0.118^{* * *}$ & $0.140^{* * *}$ & $0.141^{* * *}$ \\
\hline$R D$ & $0.289 * * *$ & $0.456^{* * *}$ & $0.356^{* * *}$ & $0.361^{* * *}$ & $0.276^{* * *}$ \\
\hline FIX & $0.357^{* * *}$ & $0.444^{* * *}$ & $0.417^{* * *}$ & $0.423^{* * *}$ & $0.295^{* * *}$ \\
\hline PHED & $0.046^{* *}$ & 0.014 & $0.035 *$ & $0.046^{* *}$ & $0.041 * *$ \\
\hline$G D P(P)$ & $0.048^{* *}$ & $0.057^{* *}$ & $0.067^{* *}$ & $0.037^{* *}$ & $0.085^{* *}$ \\
\hline$W^{*} V C$ & & & & $0.161^{* * *}$ & $0.169^{* * *}$ \\
\hline$W^{*} R D$ & & & & $0.417^{* * *}$ & $0.416^{* * *}$ \\
\hline$W^{*} F I X$ & & & & $0.468^{* * *}$ & $0.207^{* * *}$ \\
\hline$W^{*} P H E D$ & & & & -0.091 & -0.002 \\
\hline$W^{*} G D P(P)$ & & & & $0.041^{* *}$ & $0.054^{* *}$ \\
\hline$\rho$ & & $0.189 * * *$ & $0.215^{* * *}$ & $0.201 * * *$ & $0.224^{* * *}$ \\
\hline$R^{2}$ & 0.711 & 0.932 & 0.952 & 0.964 & 0.965 \\
\hline Adjust- $R^{2}$ & 0.656 & 0.845 & 0.821 & 0.867 & 0.866 \\
\hline $\log -L$ & 834 & 851 & 846 & 864 & 872 \\
\hline Hausman test & $\chi^{2}=39.851^{* * *}$ & & & & \\
\hline
\end{tabular}

The influence coefficient of venture capital on the level of industrial structure upgrading was positive, and it passed the significance level test. Venture capital has a significant role in promoting the industrial structure upgrading, although its simulative effect is weak. The main reason for this is that venture capital can invest funds in the upgrading of industrial structure, improve the specialization and advancement of production factors, and finally drive the improvement of production efficiency and the change of industrial structure. This is consistent with the research results of Liang kai (2016), Chen Zhi et al. (2010) and Yang Ye et al. (2012), that is, that venture capital can promote the upgrading of industrial structures.

From the perspective of control variables, fixed asset investment scale, research and development intensity, producer quality, and the degree of economic development can promote the regional industrial structure upgrading level. In particular, the local fixed asset investment level and R\&D intensity almost promoted the upgrading process of a local industrial structure at a significant level of $1 \%$, which indicated that both the regional fixed asset investment level and R\&D intensity have significant multiplier effects and promote the upgrading of local industrial structures. From the point of promoting effects, the R\&D level can promote the upgrading of industrial structure when its effect is significantly higher than that of venture investment. The reason for this may be that the human capital and R\&D capital investment will focus on technology development, and the use of venture capital funds may spread to the market development and enterprise management etc. This conclusion is consistent with Zhu Xiaozhong etc. [48]. 
Finally, in the SDM model, we can find that no matter what kind of spatial weight matrix is used, the coefficients of economic development degree are all positive and have passed the significance level test of $5 \%$. This indicates that the degree of economic development has obvious promotion effect on its own industrial structure upgrading. However, the $W^{*} P H E D$ coefficient under the interaction effect was negative, and none of the values passed the significance test. This shows that the index of quality of producers is not significant.

\subsubsection{Robustness Test of the Model}

In order to further verify the reliability of the empirical results of the spatial econometric model, a robustness test of the model was carried out in this paper. Beijing, Shanghai, Guangdong, Zhejiang and Jiangsu are hot spots for venture capital, so we excluded them from the robustness test. The remaining provinces have a smaller relative gap in venture capital scale, which can better reflect the impact of venture capital level on industrial structure upgrading. Based on the above analysis, the SDM was also used to test the robustness. The empirical results are shown in Table 5.

Table 5. Robustness test results.

\begin{tabular}{ccc}
\hline \multirow{2}{*}{ Variables } & \multicolumn{2}{c}{ SDM } \\
\cline { 2 - 3 } & Geographical Distance Matrix & Economic Distance Matrix \\
\hline$V C$ & $0.043^{* *}$ & $0.083^{* *}$ \\
\hline$R D$ & $0.059^{* *}$ & $0.067^{* *}$ \\
\hline$F I X$ & $0.089^{* *}$ & $0.061^{* *}$ \\
\hline$P H E D$ & 0.021 & $0.022^{*}$ \\
\hline$G D P(P)$ & $0.082^{*}$ & $0.105^{*}$ \\
\hline$W^{*} V C$ & $0.058^{* *}$ & $0.023^{* *}$ \\
\hline$W^{*} R D$ & $0.019^{* *}$ & $0.064^{* *}$ \\
\hline$W^{*} F I X$ & $0.016^{* *}$ & $0.012^{*}$ \\
\hline$W^{*} P H E D$ & -0.030 & $-0.036^{*}$ \\
\hline$W^{*} G D P(P)$ & $0.378^{*}$ & $0.124^{*}$ \\
\hline$\rho$ & $0.054^{* *}$ & $0.004^{* *}$ \\
\hline$R^{2}$ & 0.531 & 0.514 \\
\hline Adjust- $R^{2}$ & 0.503 & 0.487 \\
\hline$L o g-L$ & 521 & 514 \\
\hline Note: ${ }^{* *}$ and ${ }^{*}$ respectively mean passing significance test at the levels of $5 \%$ and $10 \%$.
\end{tabular}

It can be seen that venture capital level also has a positive effect on the development of industrial structure upgrading. From the perspective of the variable coefficient, its influence coefficient was lower than the result of data operation of all provinces, indicating that after excluding Beijing and the four other provinces, the influence degree of venture capital on industrial structure upgrading was reduced. However, the influence coefficient of venture capital still passed the significance test at the level of $5 \%$, and the influence model also passed the significance test at the level of $5 \%$, indicating that the test results are robust.

\section{Conclusions and Recommendations}

Since most of the previous literature remained in the stage of theoretical analysis, and only a few scholars have analyzed the spillover principle of the upgrading of industrial structure of venture capital from the perspective of spatial spillover, this paper tried to carry on the beneficial research. In this paper, we collected the sample data of 31 provinces in China from 2003 to 2017 . We adopted the Moran's I to test the spatial correlation between venture capital and industrial structure upgrading. Finally, a spatial econometric model was constructed to test the impact of venture capital on industrial 
structure upgrading. Therefore, unlike previous studies, this paper not only focuses on the spatial distribution and agglomeration of venture capital and industrial organization upgrading, but also focuses on their spatial externalities. Based on theoretical analysis and empirical test, the conclusions and countermeasures are as follows: Firstly, venture capital and industrial structure upgrading all have obvious spatial autocorrelation and form different agglomeration areas in local areas. Therefore, regional venture capital and industrial structure upgrading are closely related to regional location factors. China's venture capital has unique spatial attributes. Secondly, venture capital and industrial structure upgrading have obvious spatial spillover. Venture capital has a significant role in promoting industrial structure upgrading, although its simulative effect is weak. In addition, in order to further explore the influence mechanism of regional industrial structure upgrading, this paper found that the local fixed asset investment level and R\&D intensity promoted the upgrading process of local industrial structures at a significant level.

Based on the above conclusions, this paper proposes the following suggestions:

(1) China's venture capital activities are mainly concentrated in the eastern coastal zone. In recent years, the venture capital activities gradually began to transfer to the central and western regions. The elevation value of China's industrial structure has a rising trend from 2003 to 2017, indicating that China's industrial structure was gradually developing to a higher-level overall and that there is a significant spatial clustering phenomenon in the China's industrial structure upgrading level. The venture capital in the eastern region should exert its spatial spillover effect and strengthen cooperation with the western region to promote the upgrading of regional industrial structures and achieve a win-win situation.

(2) The government should guide the spatial layout of the venture capital industry actively and rationally. Through the support of the venture capital industry for high-tech enterprises and technological innovation-oriented enterprises, we can gradually phase out backward and excess capacity enterprises, actively cultivate new economic growth poles such as finance, the Internet, and new energy vehicles, and upgrade industrial structures. Regional governments should guide the technology seeking venture capital and improve the ability of venture capital enterprises to acquire, absorb, and digest any technology spillover.

(3) When formulating policies to guide the development of venture capital industry, local governments should avoid "one-size-fits-all" policies. In line with differences in venture capital, economic development, and industrial structures in different regions, the government should formulate differentiated guiding policies for venture capital. They should actively encourage, support, and guide venture capital investment in the eastern region, accumulate good experience and practices, ultimately drive the comprehensive and coordinated development of venture capital industry in the central and western regions, and promote the upgrading of domestic industrial structures. Governments should not only attach importance to the role of venture capital in promoting the upgrading of industrial structure in their own regions, but also give full play to spatial externality so that they can also promote the upgrading industrial structures in neighboring provinces.

Although this paper has conducted some meaningful studies, there are still deficiencies. For example, since the information from the venture capital industry has not been fully disclosed, the data of venture capital cannot be fully obtained. Therefore, this paper can only select representative data for research. The measurement dimension of industrial structure upgrading not only includes the relative changes among the three industrial structures, but also includes the changes in the internal composition of each industrial structure. Therefore, further studies should be conducted on the above deficiencies in the future.

Author Contributions: L.Y. had the original idea for the study and wrote the original draft. P.S. edited the manuscript and provided critical final review. More specifically, conceptualization, L.Y. and P.S.; methodology, L.Y. and J.L.; literature review, L.Y. and P.S.; empirical analysis, L.Y. and J.L.; original draft preparation, L.Y.; review and editing, P.S. 
Funding: This study was jointly supported by the National Natural Science Foundation of China (41901145), Foundation of Key Laboratory of Geospatial Technology for the Middle and Lower Yellow River Regions (GTYR201908), National Key R\&D Program of China (2018YFD1100804) and Talent Introduction Program Project of Southwest University (SWU019020).

Conflicts of Interest: The authors declare no conflict of interest.

\section{References}

1. Wang, M.; Wei, Y.; Qiu, J. Spatial Agglomeration and Urban Network of Venture Capital Investment in China. J. Financ. Econ. 2014, 40, 117-131.

2. Florida, R.; Kenney, M. Venture capital and high technology entrepreneurship. J. Bus. Venturing 1988, 3, 301-319. [CrossRef]

3. Florida, R.; Smith, D.F. Venture capital formation, investment, and regional industrialization. Ann. Assoc. Am. Geogr. 1993, 83, 434-451. [CrossRef]

4. Savaneviciene, A.; Venckuviene, V.; Girdauskiene, L. Venture capital a catalyst for start-ups to overcome the "Valley of death": Lithuanian case. Procedia Econ. Finance 2015, 26, 1052-1059. [CrossRef]

5. Li, Z.; Xu, M.; He, C.; Pan, F. Review and prospects on financial geography. Econ. Geogr. 2018, 38, 7-15.

6. Liu, G.; Liu, Y. Study on the Effect of Venture Capital on the Industrial Transformation and Upgrading. Ind. Econ. Rev. 2019, 10, 45-55.

7. French, K.; Poterba, J. Investor diversification and international equity markets. Am. Econ. Rev. 1991, 81, 222-226.

8. Martin, R.; Berndt, C.; Klagge, B.; Sunley, P. Spatial proximity effects and regional equity gaps in the venture capital market: Evidence from Germany and the United Kingdom. Environ. Plan. A 2005, 37, 1207-1231. [CrossRef]

9. Xu, Y.; Pan, F.; Jiang, X.; Qu, Y.; Liang, J. The geography and syndication investment networks of venture capital in Beijing. Prog. Geogr. 2016, 35, 358-367.

10. Stolpe, M. Distribution dynamics in European venture capital (No. 1191). Kiel Working Paper 2003.

11. Kortum, S.; Lerner, J. Assessing the Contribution of Venture Capital to Innovation. J. Econometrics 2000, 31, 674-692. [CrossRef]

12. Langeland, O. Financing innovation: The role of Norwegian venture capitalists in financing knowledge-intensive enterprises. Eur. Plann. Stud. 2007, 15, 1143-1161. [CrossRef]

13. Yao, L. Venture Capital, Regional Technological Innovation and Spatial Spillover Effects-An Empirical Research Based on the Spatial Panel Data from 31 Provinces in China. Contemp. Econ. Manag. 2018, 40, 7-12.

14. Gupta, A.K.; Sapienza, H.J. Determinants of venture capital firms' preferences regarding the industry diversity and geographic scope of their investments. J. Bus. Venturing 1992, 7, 347-362. [CrossRef]

15. Chary, T.S. Role of Venture Capital in Promotion of New Enterprises. Financ. India 2015, 19, 1003-1011.

16. Wei, Z.; Jin, Y.; Wang, J. Greenization of venture capital and green innovation of Chinese entity industry. Ecol. Indic. 2018, 51, 31-41. [CrossRef]

17. Ding, M.; Jin, X. Equity Investment E Economic Transformation and Upgrading; Zhejiang University Press: Hangzhou, China, 2011.

18. Florida, R.L.; Kenney, M. Venture capital, high technology and regional development. Reg Stud. 1988, 22, 33-48. [CrossRef]

19. Peneder, M. The impact of venture capital on innovation behaviour and firm growth. Venture Cap. 2010, 12, 83-107. [CrossRef]

20. Wang, G.; Xu, Y.; Wang, Y. An Analysis on the Impact of Technological Innovation on Industrial Transformation and Upgrading in China. East. China Econ. Manag. 2016, 3, 83-90.

21. Xu, Q.; Wang, T. On the Relationship Between the Venture Investment and the Regional Economic Development: An Empirical Study Based on the Listed Companies of the Yangtze River Delta. J. Manag. 2018, 31, 22-33.

22. Miller, H.J. Tobler's first law and spatial analysis. Ann. Assoc. Am. Geogr. 2004, 94, 284-289. [CrossRef]

23. Li, L.; Ding, Y.; Liu, Z. The Spatial Econometric Analysis of Spatial Spillover from Finance Agglomeration to Regional Economic Growth. J. Financ. Res. 2011, 5. 
24. Johansson, B.; Quigley, J.M. Agglomeration and networks in spatial economics. Pap. Reg Sci. 2004, 83, 165-176. [CrossRef]

25. Varga, A. University Research and Regional Innovation: A Spatial Econometric Analysis of Academic Technology Transfers; Kluwer Academic Publishers: Boston, MA, USA; Dordrecht, The Netherlands; London, UK, 1998.

26. Moreno, R.; Paci, R.; Usai, S. Spatial spillovers and innovation activity in European regions. Environ. Plan. A. 2005, 37, 1793-1812. [CrossRef]

27. Rey, S.J.; Janikas, M.V. Regional convergence, inequality, and space. J. Econ. Geogr. 2005, 5, 155-176. [CrossRef]

28. Le Gallo, J.; Fingleton, B. Regional growth and convergence empirics. In Handbook of Regional Science; Springer: Heidelberg, Germany; New York, NY, USA; Dordrecht, The Netherlands; London, UK, 2019; pp. 1-28.

29. Humphrey, J.; Schmitz, H. Governance and Upgrading: Linking Industrial Cluster and Global Value Chain Research; Institute of Development Studies: Brighton, UK, 2000.

30. Lall, S. Competitiveness, Technology and Skills; Edward Elgar: Cheltenham, UK, 2001.

31. Ergas, H. Does technology policy matter? In Technology and Global Industry: Companies and Nations in the World Economy; National Academic Press: Washington, DC, USA, 1987; pp. 191-245.

32. Gereffi, G. International trade and industrial upgrading in the apparel commodity chain. J. Int. Econ. 1999, 48, 37-70. [CrossRef]

33. Amin, A.; Goddard, J. Technological Change, Industrial Restructuring and Regional Development; Routledge: London, UK; New York, NY, USA, 2018.

34. Greenwood, J.; Jovanovic, B. Financial development, growth, and the distribution of income. J. Polit Econ. 1990, 98, 1076-1107. [CrossRef]

35. Chen, Z.; Yang, D. Research on Coordinated Development Strategy of Industrial Structure and Finance; Economic Publishing House: Beijing, China, 2007.

36. Jensen, C. Foreign direct investment, industrial restructuring and the upgrading of Polish exports. Appl. Econ. 2002, 34, 207-217. [CrossRef]

37. Pavlínek, P.; Domański, B.; Guzik, R. Industrial upgrading through foreign direct investment in Central European automotive manufacturing. Eur. Urban Reg. Stud. 2009, 16, 43-63. [CrossRef]

38. Galbraith, J.K.; Lu, J. Sustainable development and the Open-Door policy in China. Sustain. Dev. Open-Door Policy. China 2000.

39. Cai, H.; Xu, Y. Does Trade Openness Affect the Upgrading of China's Industrial Structure? J. Quant. Tech. Econ. 2017, 34, 3-22.

40. Wernerfelt, L.; Navas, L. The Underground Revolution in the Sino Vallery: A Comparison of Upgrading in Global and National Value; Edward Elgar Publishing: Cheltenham, UK; Northampton, MA, USA, 2004.

41. Antarciuc, E.; Zhu, Q. Almarri. Sustainable venture capital investments: An enabler investigation. Sustainability 2018, 10, 1204. [CrossRef]

42. Alperovych, Y.; Hübner, G.; Lobet, F. How does governmental versus private venture capital backing affect a firm's efficiency? Evidence from Belgium. J. Bus. Venturing 2015, 30, 508-525. [CrossRef]

43. Pan, X.; Zhang, J.; Song, M.; Ai, B. Innovation resources integration pattern in high-tech entrepreneurial enterprises. Int. Entrep. Manag. J. 2018, 14, 51-66. [CrossRef]

44. Wang, H. Historical investigation and enlightenment of industrial structure upgrading at home and abroad. Econ. Perspect. 2014, 6, 4-15.

45. Anselin, L. Spatial Econometrics: Methods and Models; Kluwer Academic Publishers: Dordrecht, The Netherlands, 1988.

46. Anselin, L. The Econometrics of Panel Data; Springer: Berlin/Heidelberg, Germany, 2008.

47. LeSage, J.; Pace, R. Interpreting spatial econometric models. In Handbook of Regional Science; Springer: Heidelberg, Germany; New York, NY, USA; Dordrecht, The Netherlands; London, UK, 2014; pp. 1535-1552.

48. Zhu, X.Z. A review on the role of venture capital in technological innovation. Financ. Theory. Pract. 2008, 3, 102-106. 